\title{
Prediction Performance of an Artificial Neural Network Model for the Amount of Cooling Energy Consumption in Hotel Rooms
}

\author{
Jin Woo Moon ${ }^{1, *}$, Sung Kwon Jung ${ }^{2}$, Yong Oh Lee ${ }^{3}$ and Sangsun Choi ${ }^{3}$ \\ 1 Department of Building \& Plant Engineering, Hanbat National University, Daejeon 305-719, Korea \\ 2 Department of Architectural Engineering, Dankook University, Yongin-si 448-701, Korea; \\ E-Mail: jskstrm@umich.edu
}

3 Digital Media \& Communications Research \& Design Center, Samsung Electronic, Suwon-si 443-742, Gyeonggi-do, Korea; E-Mails: yongoh.lee@samsung.com (Y.O.L.); sangsun21.choi@samsung.com (S.C.)

* Author to whom correspondence should be addressed; E-Mail: jwmoon@hanbat.ac.kr; Tel.: +82-42-821-1183; Fax: +82-42-821-1175.

Academic Editor: Hossam A. Gabbar

Received: 4 June 2015 / Accepted: 24 July 2015 / Published: 5 August 2015

\begin{abstract}
This study was conducted to develop an artificial neural network (ANN)-based prediction model that can calculate the amount of cooling energy during the setback period of accommodation buildings. By comparing the amount of energy needed for diverse setback temperatures, the most energy-efficient optimal setback temperature could be found and applied in the thermal control logic. Three major processes that used the numerical simulation method were conducted for the development and optimization of an ANN model and for the testing of its prediction performance, respectively. First, the structure and learning method of the initial ANN model was determined to predict the amount of cooling energy consumption during the setback period. Then, the initial structure and learning methods of the ANN model were optimized using parametrical analysis to compare its prediction accuracy levels. Finally, the performance tests of the optimized model proved its prediction accuracy with the lower coefficient of variation of the root mean square errors (CVRMSEs) of the simulated results and the predicted results under generally accepted levels. In conclusion, the proposed ANN model proved its potential to be applied to the thermal control logic for setting up the most energy-efficient setback temperature.
\end{abstract}


Keywords: setback temperature; cooling energy consumption; artificial neural network; predictive and adaptive controls; accommodation

\section{Introduction}

With the period in which people spend their daily life in an indoor space having increased to $90 \%$, the proper conditioning of the indoor environment quality (IEQ) has become a significant factor of the quality of life of the occupants [1]. The IEQ is associated with diverse components such as the thermal quality, light quality, air quality, and acoustic quality. In addition to the importance of providing the proper IEQ, these components are also deeply related to the building energy efficiency, environmental impact, and economic benefits.

Thermal quality (TQ) is one of the key components of the creation of a proper IEQ. The indoor thermal quality is complexly dependent on various thermal factors such as the indoor temperature, humidity, mean radiant temperature, and air velocity. These factors are affected by the heat transfer between the indoor and outdoor spaces, and by the indoor heat generation. Heat transfer consists of heat conduction and convection through building envelopes and solar radiation. In addition, indoor heat is generated by the occupants, lighting fixtures, and equipment. Proper planning of buildings can effectively control the amount of heat transfer and indoor heat generation [2-4].

Moreover, the thermal quality and the energy efficiency of buildings are closely correlated with the operating strategy of thermal control systems. Proper operation of heating, ventilating, and air conditioning systems (HVACs) can provide comfortable temperature and humidity conditions, and can enhance energy efficiency, which would reduce $\mathrm{CO}_{2}$ generation that will decrease environmental damage [5].

Numerous studies have been conducted to propose a better control strategy for thermal systems. Among these efforts, artificial intelligence (AI), which is the study and design of intelligent agents that perceive their surrounding environment and take actions to maximize its chances of success, has been increasingly applied in the thermal control algorithm. AI can be successfully applied to the science and engineering of making intelligent machines. Thus, it can be defined as theories or methods that increase the potential of systems or logics to be used successfully based on their intelligent and smart works [1].

An artificial neural network (ANN) is a type of artificial intelligence. It is a computational model that uses the biological processes in the human brain [6]. Its advantage is that it does not require complex knowledge of system dynamics and can be successfully applied to non-linear systems or systems with unclear dynamics [1]. Based on the two major processes - (i) the feed-forward process for calculating the output from a series of inputs, and (ii) the back-propagation process for iterative self-learning - it was found that the predictive and adaptive controls of the systems are feasible.

The superiority of the ANN-based models over the existing mathematical models, such as of the proportional-integral-derivative (PID) models or regression models, has been widely proven [7]. The ANN model presented the more accurate prediction results for the heating and cooling loads [8-10] and energy consumption [11-17]. The ANN model successfully predicted the thermal comfort level as well as indoor temperature conditions [18-20]. In addition, after using the ANN model in the building thermal controls, the indoor thermal environment was more comfortably conditioned based on the 
reduced overcooling and overheating, and the amount of energy consumption of the heating and cooling systems was significantly reduced [20-32].

Similar to other types of buildings, the thermal environment in accommodation buildings and its controls also need to be prudently managed to provide thermal comfort to the occupants and to improve the energy efficiency of systems. Despite these similar requirements, hotel rooms have two distinctive features. First, their indoor space is generally unoccupied at daytime and occupied at nighttime. Thus, thermal comfort is not an important factor at daytime, when the room is empty. Second, energy efficiency may not be among the occupant's concerns. Normally, the occupant pays the designated lodging charge without an extra fee for indoor thermal conditioning. The occupant may operate the heating and cooling systems in excess of their required degree. For example, general hotel users do not recognize the necessity of the setback application or the proper setback temperature of heating and cooling systems.

Thus, an active management process is required for the proper operation of thermal control systems in accommodation. The optimal setback temperature for heating and cooling systems needs to be considered in the expert system for improving energy efficiency. From this aspect, this study aimed at proposing an artificial neural network (ANN) model that can predict the amount of cooling energy needed during the setback period for various setback temperatures. The proposed ANN model calculates the amount of cooling energy during the unoccupied period for the diverse degrees of setback temperature of the cooling system. The optimal setback temperature, which consumed the least amount of cooling energy, can be applied as the most energy-efficient strategy.

The proposed ANN model in this study will be applied to the control logic which will be developed in the future study. With the use of the optimal setback temperature in the control logic, energy efficiency in accommodation buildings is expected to be improved.

\section{Development of a Prediction Model}

A logic framework for indoor thermal control systems, which can deliver indoor thermal comfort and building energy efficiency in a synthetic manner, has been proposed by Moon and Kim [1]. For improving the thermal comfort and building energy efficiency, the set-point and setback temperatures were mentioned to be optimally determined using the prediction models such as ANN.

Three major processes, as shown in Figure 1, were performed in this study for the development of an ANN-based prediction model. The first process involved the organizing of the initial model. In this process, the input, hidden and output neurons, initial number of hidden layers, and learning methods were determined. The second process optimizes the initial values of the ANN model such as the number of hidden layers and the learning methods to produce more stable and accurate outputs. The third step evaluates the prediction performance of the optimized ANN model. The accuracy of the prediction results of the ANN model was analyzed by comparing the predicted values with the numerically simulated values. The proven prediction accuracy of the ANN model showed its potential to be successfully applied to the control logic. 


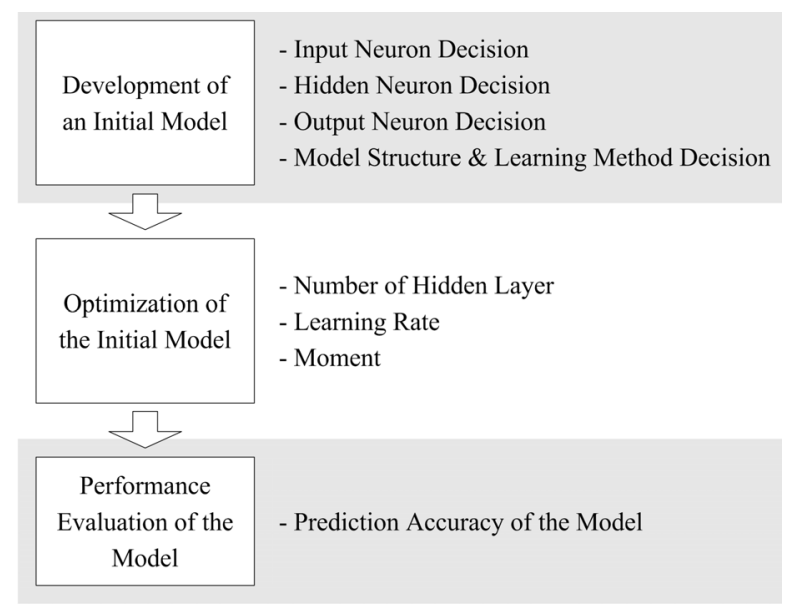

Figure 1. Development process of the prediction model.

\subsection{Development of the Initial Model}

The composition of the initial ANN model is shown in Figure 2 and summarized in Table 1. MATLAB (Matrix Laboratory) [30] and its neural network toolbox were used to develop the initial ANN model. The input variables for the prediction of the output variable, which is the amount of cooling energy consumption during the setback period (ENSETBACK, $\mathrm{kWh}$ ), were composed of the setback temperature (TEMPSETBACK, ${ }^{\circ} \mathrm{C}$ ), outdoor air temperature $\left(\right.$ TEMPouT, $\left.{ }^{\circ} \mathrm{C}\right)$, average outdoor air temperature from an hour earlier to the last control cycle (TEMPouT, AVE, nStep-60 nStep-1, ${ }^{\circ} \mathrm{C}$ ), average outdoor air temperature from two hours earlier to an hour earlier (TEMPouT, AVE, nStep-120 nStep-61, ${ }^{\circ} \mathrm{C}$ ), average outdoor air temperature from three hours earlier to two hours earlier (TEMPouT, AVE, nStep-180 nStep-121, ${ }^{\circ} \mathrm{C}$ ), average outdoor air temperature from four hours earlier to three hours earlier (TEMPout, AVE, nStep-240 nStep-181, ${ }^{\circ} \mathrm{C}$ ), average outdoor air temperature from five hours earlier to four hours earlier (TEMPOUT, AVE, nStep-300 nStep-241, ${ }^{\circ} \mathrm{C}$ ), average outdoor air temperature from six hours earlier to five hours earlier (TEMPout, AVE, nStep-360 nStep-301, ${ }^{\circ} \mathrm{C}$ ), and daytime setback period (ENSETBACK, minutes).

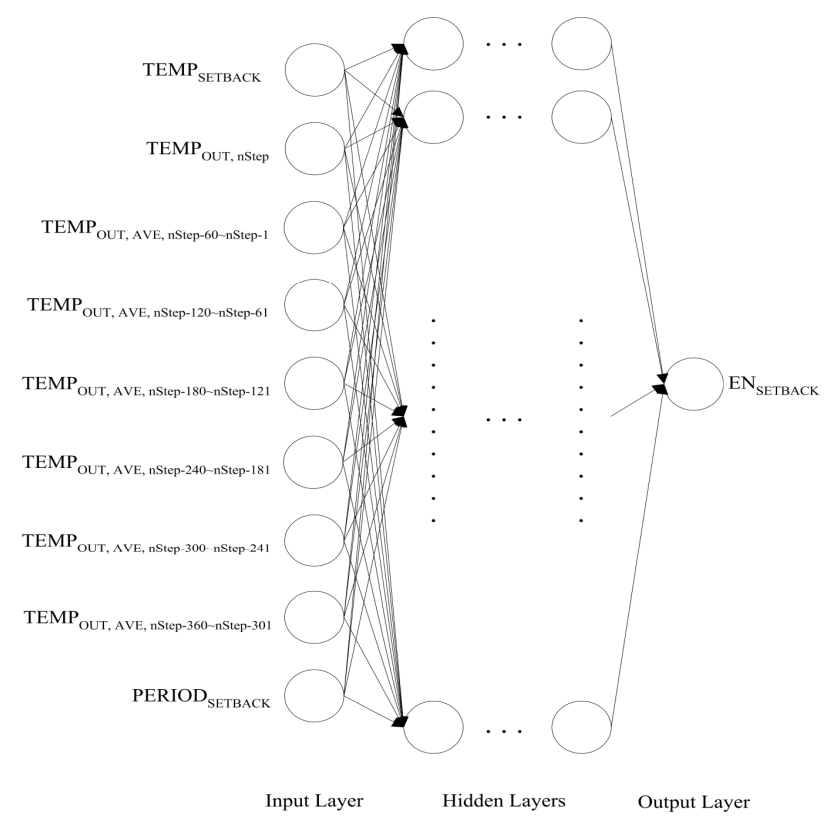

Figure 2. Structure of the initial ANN model. 
Table 1. Composition of the initial prediction model.

\begin{tabular}{|c|c|c|}
\hline & Parameters & Components and values \\
\hline \multirow{15}{*}{ Structure } & \multirow{10}{*}{ Input layer } & Number of neurons: 9 \\
\hline & & i) TEMP \\
\hline & & ii) $\mathrm{TEMP}_{\text {OUT, nStep }}$ \\
\hline & & iii) TEMP ${ }_{\text {OUT, AVE, nStep-60 nStep-1 }}$ \\
\hline & & iv) TEMP \\
\hline & & v) TEMP \\
\hline & & vi) TEMP OUT, AVE, nStep-240 nStep-181 \\
\hline & & vii) TEMP ${ }_{\text {OUT, AVE, nStep-300 nStep-241 }}$ \\
\hline & & viii) TEMP OUT, AVE, nStep-360 nStep-301 \\
\hline & & ix) PERIOD SETBACK $_{\text {S }}$ \\
\hline & \multirow{3}{*}{ Hidden layer } & Number of neurons: 19 using \\
\hline & & $\mathrm{N}_{\mathrm{h}}=2 \mathrm{~N}_{\mathrm{i}}+1[11,33]$ \\
\hline & & Number of hidden Layer: 1 \\
\hline & \multirow{2}{*}{ Output layer } & Number of neuron: 1 \\
\hline & & i) EN $_{\text {SETBACK }}$ \\
\hline \multirow{2}{*}{ Transfer function } & Hidden neurons & Tangent sigmoid \\
\hline & Output neurons & Pure linear \\
\hline \multirow{8}{*}{ Training method } & Goal & $0.01 \mathrm{kWh}$ (mean square error) \\
\hline & Epoch & 1,000 times \\
\hline & Learning rate & $0.6[34]$ \\
\hline & Moment & $0.4[34]$ \\
\hline & Algorithm & Levenberg-marquardt [1,35-37] \\
\hline & Number of doto cetc & 196 using \\
\hline & Number of data sets & $\mathrm{N}_{\mathrm{d}}=\left(\mathrm{N}_{\mathrm{h}}-\left(\mathrm{N}_{\mathrm{i}}+\mathrm{N}_{\mathrm{o}}\right) / 2\right)^{2}[12]$ \\
\hline & Data management technique & Sliding-window method \\
\hline
\end{tabular}

The relationship between the setback temperature and the amount of energy consumption, as well as between the setback period and the amount of energy consumption, had been proven in the previous study [38]. The current and past outdoor temperatures also showed a significant relationship with the amount of energy consumption for thermal conditioning in buildings. The input values for each neuron were normalized between 0 and 1 using Equation 1. The normalized values were represented as 23 to $40{ }^{\circ} \mathrm{C}$ for TEMPsetback, -20 to $40{ }^{\circ} \mathrm{C}$ for TEMPout and TEMPAVE, and 0 to 10 hours for PERIODSETBACK.

$$
\text { (VALACT-VALMIN) / (VALMAX-VALmiN) }
$$

The amount of cooling energy consumption (ENSETBACK) from the ANN model indicated the summation of the cooling energy during the setback period and the cooling energy needed to restore the indoor temperature to the normal set-point temperature. For example, when the setback temperature is $30{ }^{\circ} \mathrm{C}$ during the setback period and the normal set-point temperature is $23{ }^{\circ} \mathrm{C}$, the cooling system will condition the indoor temperature to keep it at $30{ }^{\circ} \mathrm{C}$ during the setback period. To achieve this, a certain amount of cooling energy will be consumed. Moreover, when the setback period ends the set-point temperature returns to normal. For a certain period, the cooling system needs 
to work to restore the indoor temperature to $23{ }^{\circ} \mathrm{C}$. This is the cooling energy required to normalize the indoor temperature. Since the cooling energy for the restoration was increased when the setback temperature was higher, the optimal setback temperature must be determined to reduce the overall cooling energy consumption.

The number of hidden layers was initially determined as 1 , and the number of hidden neurons, as 19, using the equation in Table 1. For the transfer functions, tangent-sigmoid and pure linear functions were used for the hidden and output neurons, respectively. In addition, a 0.0 minute goal, 1000 times epoch, 0.6 learning rate, 0.4 moment, and the Levenberg-Marquardt algorithm were used for the model training. The optimal number of hidden layers, learning rate, and moment were found in the optimization process.

A total of 196 data sets for initial training were collected based on the equation in Table 1, and the sliding-window method was used to manage the training data sets. In addition, 100 data sets for model optimization and 100 data sets for performance evaluation were prepared. Data sets for model training and evaluation were numerically collected incorporating and MATLAB (Matrix Laboratory) software [39] and TRNSYS (Transient Systems Simulation) [40].

Nine identical modules were modeled for data collection, and the data sets were collected from a module at their center, as shown in Figure 3. Figure 4 shows the modeling result of the test building. The features of the test location, dimensions, envelope insulation, infiltration rate, internal gain, and applied system are summarized in Table 2. The cooling system in the 56a-TRNFlow component was not confined to have a specific type. Instead, the method and capacity of the heat removal from the space were determined as convective and $8901 \mathrm{~kJ} / \mathrm{hr}$, respectively. The roles of seven types of components of TRNSYS software are summarized in Table 3.

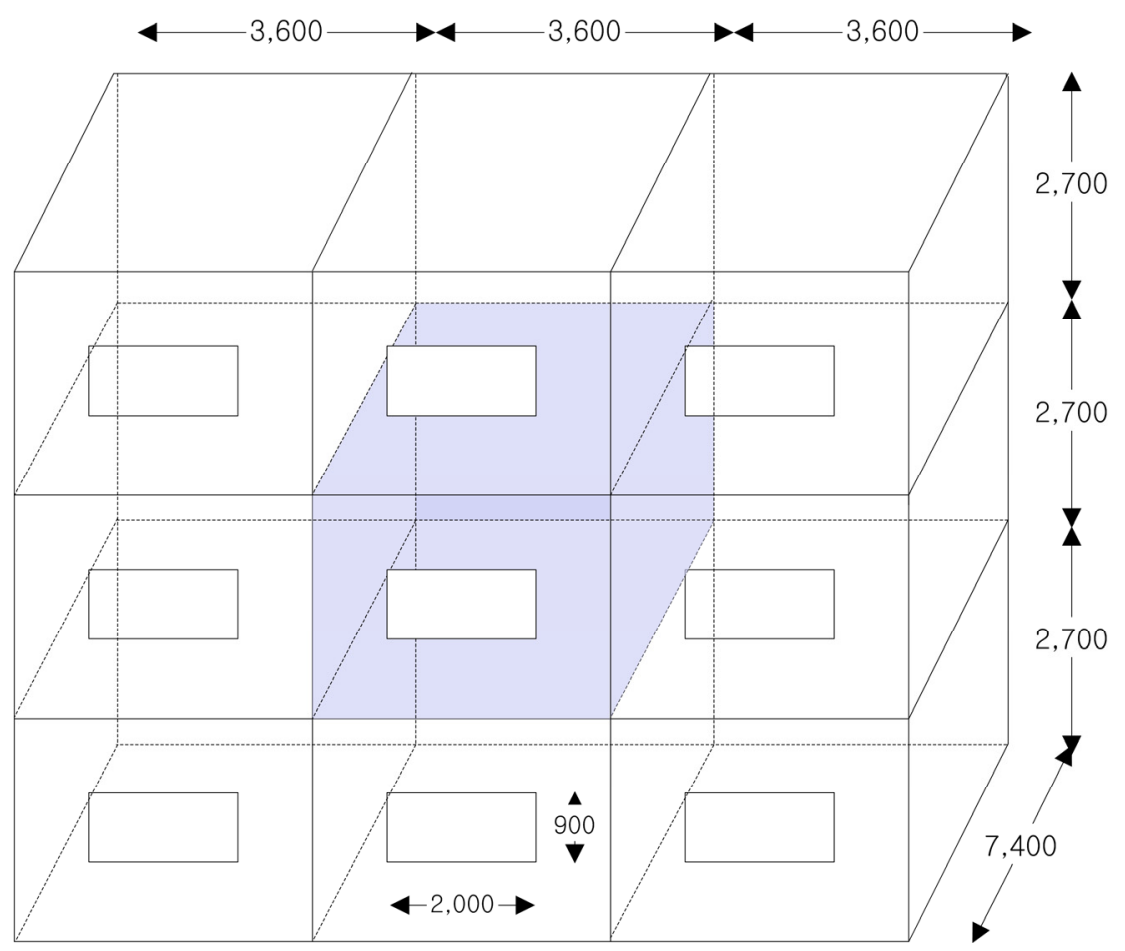

Figure 3. Test building (unit: $\mathrm{mm}$ ). 


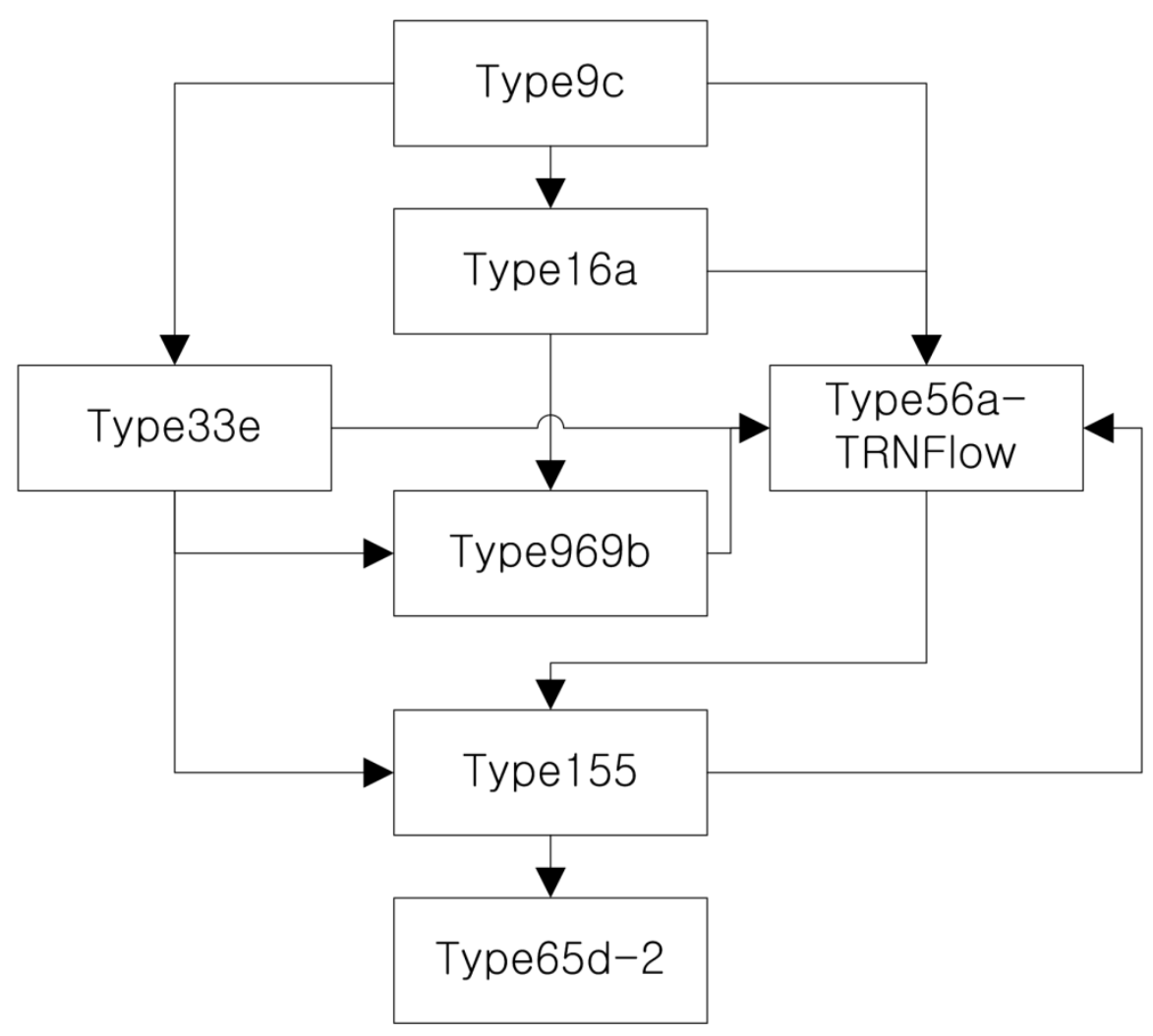

Figure 4. Composition of the simulation model.

Table 2. Features of the test building.

\section{Components}

\section{Contents}

Location and weather data

Site

Climate

conditions
Seoul, South Kroea (latitude: $37.56^{\circ} \mathrm{N}$, longitude: $126.98^{\circ} \mathrm{E}$ ) and TMY2

Hot and humid in summer: $23.5^{\circ} \mathrm{C}$ of air temperature and $72.7 \%$ of relative humidity from June to September in average

Cold in winter: $1.7^{\circ} \mathrm{C}$ of air temperature and $59.1 \%$ of relative humidity from November to February in average

\begin{tabular}{|c|c|c|}
\hline \multirow{2}{*}{ Dimension } & Module & $\begin{array}{c}26.64 \mathrm{~m}^{2} \\
3.6 \mathrm{~m} \text { wide } \times 7.4 \mathrm{~m} \text { deep } \times 2.7 \mathrm{~m} \text { high }\end{array}$ \\
\hline & Window & $\begin{array}{c}1.8 \mathrm{~m}^{2} \\
2.0 \mathrm{~m} \text { wide } \times 0.9 \mathrm{~m} \text { high }\end{array}$ \\
\hline \multirow{3}{*}{$\begin{array}{c}\text { Envelope } \\
\text { insulation } \\
{\left[\mathrm{m}^{2} \mathrm{~K} / \mathrm{W}\right]} \\
{[41]}\end{array}$} & Exterior walls & 2.801 \\
\hline & $\begin{array}{l}\text { Interior walls, } \\
\text { roof and floor }\end{array}$ & 0.492 \\
\hline & Windows & 0.353 \\
\hline \multicolumn{2}{|c|}{ Infiltration rate [41] } & $0.7 \mathrm{ACH}$ \\
\hline \multicolumn{2}{|c|}{ Internal gain } & $\begin{array}{c}1 \text { occupant with seated, light work, typing } \\
1 \text { computer and printer } \\
5 \mathrm{~W} / \mathrm{m}^{2} \text { lighting fixtures }\end{array}$ \\
\hline \multicolumn{2}{|c|}{ Applied system [42] } & Convective cooling: $8901 \mathrm{~kJ} / \mathrm{hr}$ heat removal \\
\hline
\end{tabular}


Table 3. Roles of the TRNSYS components.

\begin{tabular}{cc}
\hline Components & Roles \\
\hline Type9c & $\begin{array}{c}\text { Reading the TMY2 weather file } \\
\text { Transferring the weather data to the Type16a, Type33e, and Type56a-TRNFlow } \\
\text { Calculating the amount of solar radiation on the test building surface } \\
\text { Transferring the data to Type69b } \\
\text { Calculating the sky temperature }\end{array}$ \\
Tpe69b & $\begin{array}{c}\text { Transferring the data to the Type56a-TRNFlow } \\
\text { Calculating the outdoor dew-point temperature } \\
\text { Type33e }\end{array}$ \\
Calculating the indoor temperature of the test building \\
Type56a-TRNFlow \\
Type155 \\
Connecting the MATBAL and ANN models \\
Producing training data sets \\
Producing the output file
\end{tabular}

Data sets for training, optimization, and evaluation were collected during the cooling season from June 01 to September 30. Different degrees of TEMPSETBACK from $23{ }^{\circ} \mathrm{C}$ to $40{ }^{\circ} \mathrm{C}$ were applied to obtain the EN SETBACK. The PERIODSETBACK was fixed 10 hours assuming the unoccupied period was from 8:00 to 18:00. Thus, a variety of ENSETBACK according to the change of TEMPSETBACK was collected for model training, optimization, and evaluation. Examples of data sets, which are composed of a series of input variables and one output variable, are presented in Table 4.

Table 4. Composition of the training data sets.

\begin{tabular}{|c|c|c|c|c|c|c|}
\hline Data & & 1 & 2 & 3 & 4 & 5 \\
\hline \multirow{9}{*}{$\begin{array}{l}\text { Input components (actual value in } \\
\text { parenthesis, }{ }^{\circ} \mathrm{C} \text { for TEMP and } \\
\text { minutes for PERIOD) }\end{array}$} & TEMPSETBACK & $\begin{array}{c}0.00 \\
(23.00)\end{array}$ & $\begin{array}{c}0.00 \\
(23.00)\end{array}$ & $\begin{array}{c}0.00 \\
(23.00)\end{array}$ & $\begin{array}{c}0.00 \\
(23.00)\end{array}$ & $\begin{array}{c}0.00 \\
(23.00)\end{array}$ \\
\hline & TEMPout, nStep & $\begin{array}{c}0.65 \\
(19.07)\end{array}$ & $\begin{array}{c}0.67 \\
(20.15)\end{array}$ & $\begin{array}{c}0.66 \\
(19.65)\end{array}$ & $\begin{array}{c}0.70 \\
(21.78)\end{array}$ & $\begin{array}{c}0.68 \\
(20.72)\end{array}$ \\
\hline & TEMPouT, AVE, nStep-60 nStep-1 & $\begin{array}{c}0.64 \\
(18.29)\end{array}$ & $\begin{array}{c}0.65 \\
(19.28)\end{array}$ & $\begin{array}{c}0.65 \\
(19.10)\end{array}$ & $\begin{array}{c}0.68 \\
(21.01)\end{array}$ & $\begin{array}{c}0.66 \\
(19.70)\end{array}$ \\
\hline & TEMPouT, AVE, nStep-120 nStep-61 & $\begin{array}{c}0.64 \\
(18.17)\end{array}$ & $\begin{array}{c}0.63 \\
(17.54)\end{array}$ & $\begin{array}{c}0.63 \\
(18.04)\end{array}$ & $\begin{array}{c}0.66 \\
(19.47)\end{array}$ & $\begin{array}{c}0.63 \\
(17.70)\end{array}$ \\
\hline & TEMPouT, AVE, nStep-180 nStep-121 & $\begin{array}{c}0.65 \\
(18.89)\end{array}$ & $\begin{array}{c}0.60 \\
(15.83)\end{array}$ & $\begin{array}{c}0.62 \\
(16.99)\end{array}$ & $\begin{array}{c}0.63 \\
(17.96)\end{array}$ & $\begin{array}{c}0.60 \\
(15.73)\end{array}$ \\
\hline & TEMPouT, AVE, nStep-240 nStep-181 & $\begin{array}{c}0.66 \\
(19.62)\end{array}$ & $\begin{array}{c}0.59 \\
(15.51)\end{array}$ & $\begin{array}{c}0.61 \\
(16.58)\end{array}$ & $\begin{array}{c}0.63 \\
(17.90)\end{array}$ & $\begin{array}{c}0.59 \\
(15.19)\end{array}$ \\
\hline & TEMPout, AVE, nStep-300 nStep-241 & $\begin{array}{c}0.67 \\
(20.34)\end{array}$ & $\begin{array}{c}0.60 \\
(15.97)\end{array}$ & $\begin{array}{c}0.61 \\
(16.54)\end{array}$ & $\begin{array}{c}0.64 \\
(18.66)\end{array}$ & $\begin{array}{c}0.59 \\
(15.49)\end{array}$ \\
\hline & TEMPouT, AVE, nStep-360 nStep-301 & $\begin{array}{c}0.68 \\
(21.06)\end{array}$ & $\begin{array}{c}0.61 \\
(16.45)\end{array}$ & $\begin{array}{c}0.61 \\
(16.53)\end{array}$ & $\begin{array}{c}0.66 \\
(19.43)\end{array}$ & $\begin{array}{c}0.60 \\
(15.82)\end{array}$ \\
\hline & PERIODSETBACK & $\begin{array}{r}1.00 \\
(600) \\
\end{array}$ & $\begin{array}{r}1.00 \\
(600) \\
\end{array}$ & $\begin{array}{r}1.00 \\
(600) \\
\end{array}$ & $\begin{array}{r}1.00 \\
(600) \\
\end{array}$ & $\begin{array}{r}1.00 \\
(600) \\
\end{array}$ \\
\hline $\begin{array}{l}\text { Output component, minutes } \\
\text { (actual value in parenthesis, } \mathrm{kWh} \text { ) }\end{array}$ & EN $_{\text {SETBACK }}$ & $\begin{array}{l}126.00 \\
(5.19)\end{array}$ & $\begin{array}{l}192.00 \\
(7.91)\end{array}$ & $\begin{array}{l}157.00 \\
(6.47)\end{array}$ & $\begin{array}{l}146.00 \\
(6.02)\end{array}$ & $\begin{array}{l}172.00 \\
(7.09)\end{array}$ \\
\hline
\end{tabular}




\subsection{Optimization of the Initial Model}

To produce more accurate and stable prediction results from the prediction model, the structure and the training methods of the initial ANN model were optimized using a parametrical optimization process based on the method used in the previous study [2,34,43].

The numbers of hidden learning rates and moments were sequentially optimized. When the first component (i.e., the number of hidden layers) was used with a target variable to be optimized, the other components (i.e., the learning rate and moment) were fixed as the initial values. After the optimal value of the first component was determined, the next component (i.e., the learning rate) was optimized. In this case, the first component (i.e., the number of hidden layers) was fixed as the optimal value, and the last component (i.e., the moment) was fixed as the initial value. This process was conducted until the optimal value of the last component (i.e., the moment) was found. The parametrical values used to optimize each component are summarized in Table 5.

One hundred data sets were collected for the ANN model optimization from the identical simulation model explained in Section 2.1. The coefficient of variation of the root mean square errors (CVRMSEs) (Equation 2) of the predicted values $\left(\mathrm{S}_{\mathrm{i}}\right)$ and the simulated values $\left(\mathrm{M}_{\mathrm{i}}\right)$ were calculated for each parametrical value. The value that produced the smallest CVRMSE was determined as the optimal value of each component.

Table 5. Parametrically tested values for optimizing the ANN components.

\begin{tabular}{cccccccccccc}
\hline Components to be optimized & \multicolumn{10}{c}{ Parametrical values to be tested } \\
\hline Number of hidden layer & 1 & 2 & 3 & 4 & 5 & 6 & 7 & 8 & 9 & 10 \\
Learning rate & 0.1 & 0.2 & 0.3 & 0.4 & 0.5 & 0.6 & 0.7 & 0.8 & 0.9 & 1.0 \\
Moment & 0.1 & 0.2 & 0.3 & 0.4 & 0.5 & 0.6 & 0.7 & 0.8 & 0.9 & 1.0 \\
\hline & CVRMSE $=\sqrt{\frac{\sum_{\mathrm{i}=1}^{\mathrm{n}}(\mathrm{Mi}-\mathrm{Si})^{2}}{\mathrm{n}}} /$ Mavr $\times 100$ \\
& $\sqrt{10}$
\end{tabular}

\subsection{Performance Evaluation of the Optimized ANN Model}

The prediction performance of the optimized ANN model was tested using the 100 data sets. Through the comparison of the CVRMSEs of the predicted (Si) and simulated (Mi) amounts of cooling energy, the prediction accuracy and stability of the developed ANN model was validated. This validity will support the applicability of the proposed ANN model to the thermal control logic for improving building energy efficiency.

\section{Results Analysis}

\subsection{Initial Model and Optimization}

The performance of the initial model was statistically investigated using the analysis of variance (ANOVA) test and the mean squared errors (MSE) between the collected data from simulation and the predicted data from the ANN model for the amount of heat removal during the unoccupied period. For 100 cases, the $\mathrm{R}^{2}$ between simulated values and predicted values was 0.4886 as shown in Figure 5 
and summarized in Table 6 , and the MSE was $0.768 \mathrm{kWh}^{2}$. Based on this initial model, the optimization process was conducted for more accurate and stable prediction.

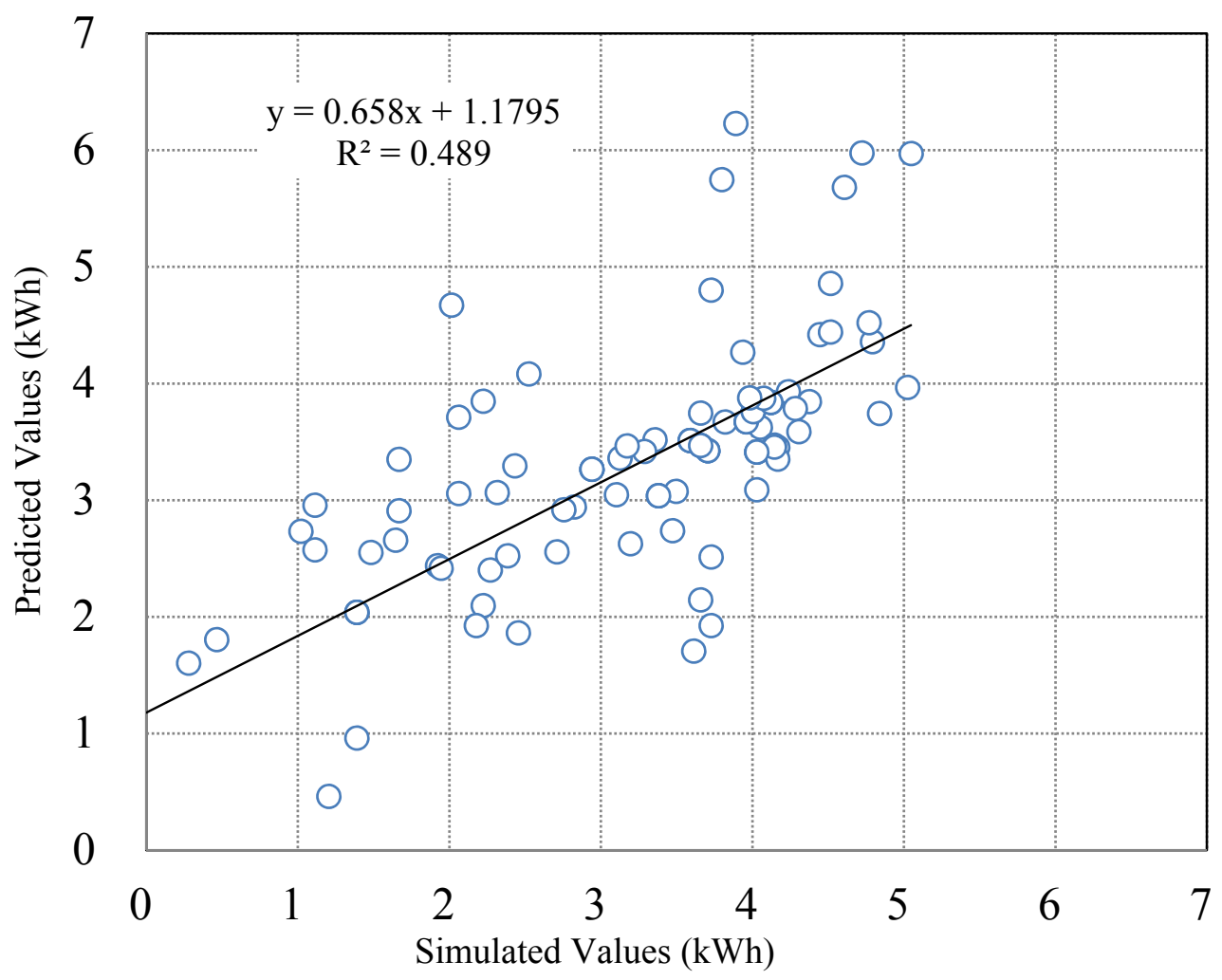

Figure 5. Relationship between the simulated values and the predicted values for the amount of heat removal during the unoccupied period.

Table 6. ANOVA test result between the simulated values and the predicted values.

\begin{tabular}{|c|c|c|c|c|c|c|c|}
\hline \multirow{2}{*}{$\begin{array}{c}\text { Independent } \\
\text { variables }\end{array}$} & \multicolumn{2}{|c|}{$\begin{array}{c}\begin{array}{c}\text { Unstandardized } \\
\text { coefficients }\end{array} \\
\end{array}$} & \multirow[t]{2}{*}{$\mathbf{t}$} & \multirow[t]{2}{*}{ Significance. } & \multicolumn{3}{|c|}{ ANOVA } \\
\hline & B & Std. error & & & $\mathbf{R 2}$ & $F(1,54)$ & Significance. \\
\hline Predicted Values & 0.658 & 0.068 & 9.677 & $<0.001$ & 0.489 & 93.642 & $<0.001$ \\
\hline
\end{tabular}

The comparison results for the prediction accuracy of the ANN models, which had different values for the structure and learning method, were compared for determining optimal ANN model as shown in Figures 6-8. The accuracy was compared with the difference between the predicted values from the ANN model $\left(\mathrm{S}_{\mathrm{i}}\right)$ and the simulated values $\left(\mathrm{M}_{\mathrm{i}}\right)$.

In the first step for finding the optimal number of hidden layers, the least CVRMSE between $\mathrm{S}_{\mathrm{i}}$ and $\mathrm{M}_{\mathrm{i}}$ was produced with three hidden layers, as presented in Figure 6. At this step, the learning rate and moment were fixed as initially determined at 0.6 and 0.4, respectively. The CVRMSE (\%) ranged from $27.72 \%$ to $76.02 \%$ for the one to 10 hidden layers. The least value, when the ANN model used three hidden layers, was $27.72 \%$, whereas the initial model with one hidden layer produced a much higher value: $41.14 \%$. Thus, the modified ANN model was changed to have three hidden layers.

In the second step for determining the optimal value of the learning rate, the learning rate was parametrically changed from 0.1 to 1.0 , as shown in Figure 7 . The number of hidden layers was set as 
three, as found in the previous step, and the moment was fixed at its initial value of 0.4. The CVRMSE values ranged from $27.72 \%$ to $42.27 \%$. The lowest value was presented when the initial value of the learning rate (0.6) was applied. Thus, the learning rate of the ANN model was not revised to 0.6.

The third step was conducted to find the optimal value of the moment. Identical to the previous step, the moment was parametrically changed from 0.1 to 1.0, as shown in Figure 8. At this step, the number of hidden layers and the learning rate were fixed at the optimal values of 3 and 0.6 , respectively. The CVRMSE ranged from $22.77 \%$ to $43.91 \%$, and the lowest value was produced from a model with a moment of 0.2 . The amount of MBE was $22.77 \%$. Thus, the optimal model was determined to have a moment of 0.2 . Based on the three steps conducted for finding the optimal structure and learning methods of the ANN, it was decided that the optimal ANN model has three hidden layers, a 0.6 learning rate, and a moment of 0.2 .

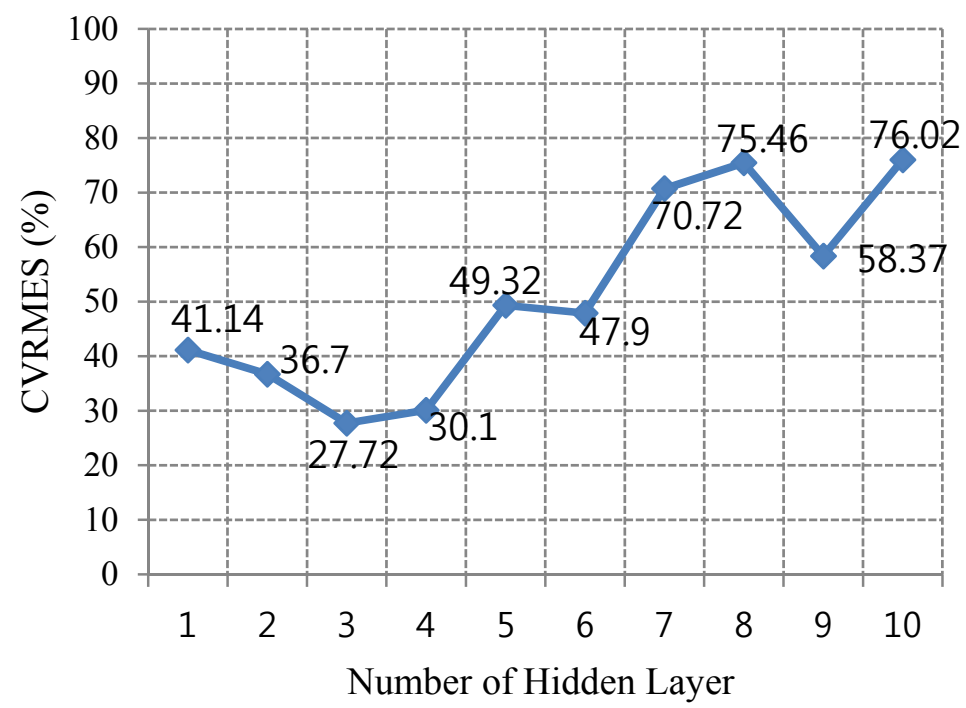

Figure 6. Mean bias error (MBE) by a different number of hidden layers.

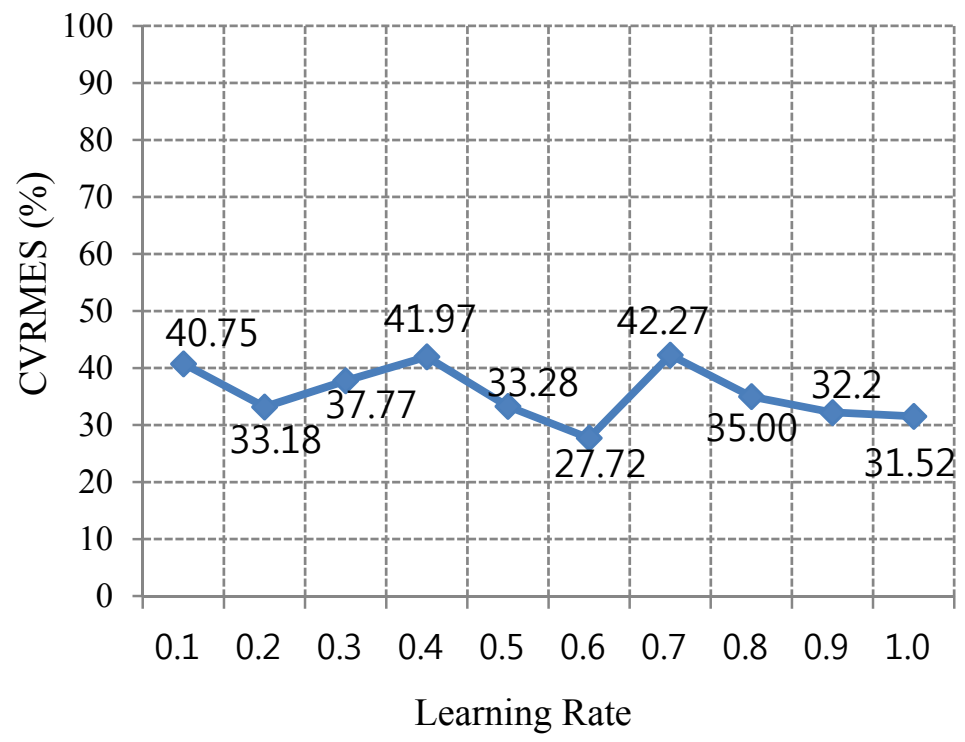

Figure 7. MBE by a different learning rate. 


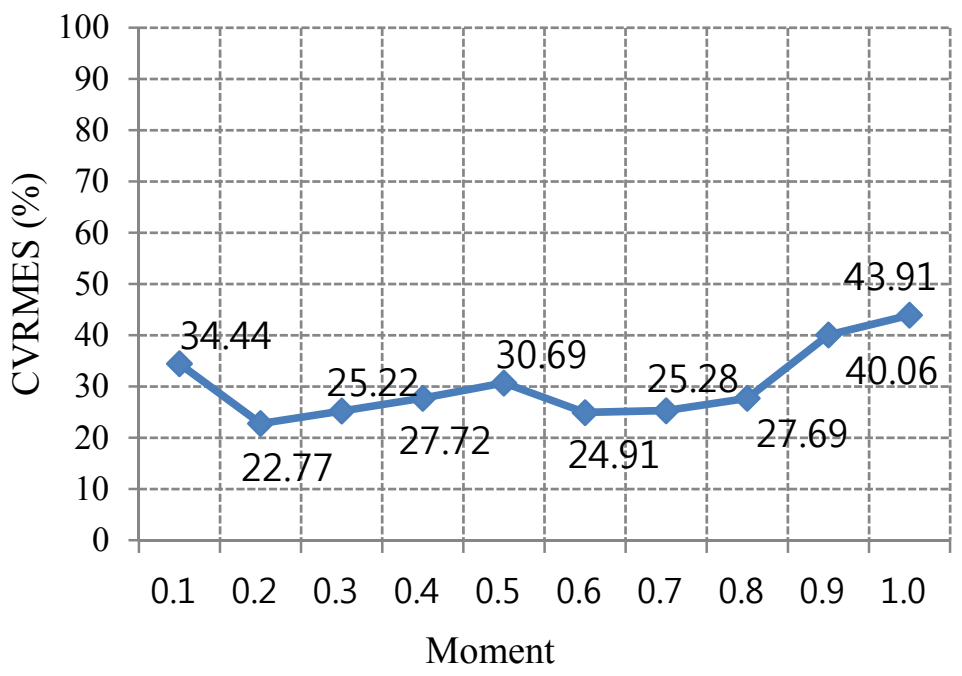

Figure 8. MBE by a different moment.

\subsection{Performance of the Optimized Model}

The performance of the optimized ANN model was evaluated according to its prediction accuracy. For the evaluation, data sets from the simulation model explained in Section 2.1 were required to be checked. Figure 9 shows the relationship between the setback temperature and the amount of heat removal by the cooling system. As the higher setback temperature was applied during the unoccupied period, the amount of heat removal was decreased. When the setback temperatures were over $30{ }^{\circ} \mathrm{C}$, the amounts of heat removal were all close to $0.0 \mathrm{kWh}$, which means the indoor temperature did not reach the degree requiring cooling operation. Thus, for the performance evaluation of the ANN model, the data sets were collected for cases when the setback temperatures between $23{ }^{\circ} \mathrm{C}$ and $30{ }^{\circ} \mathrm{C}$ were applied.

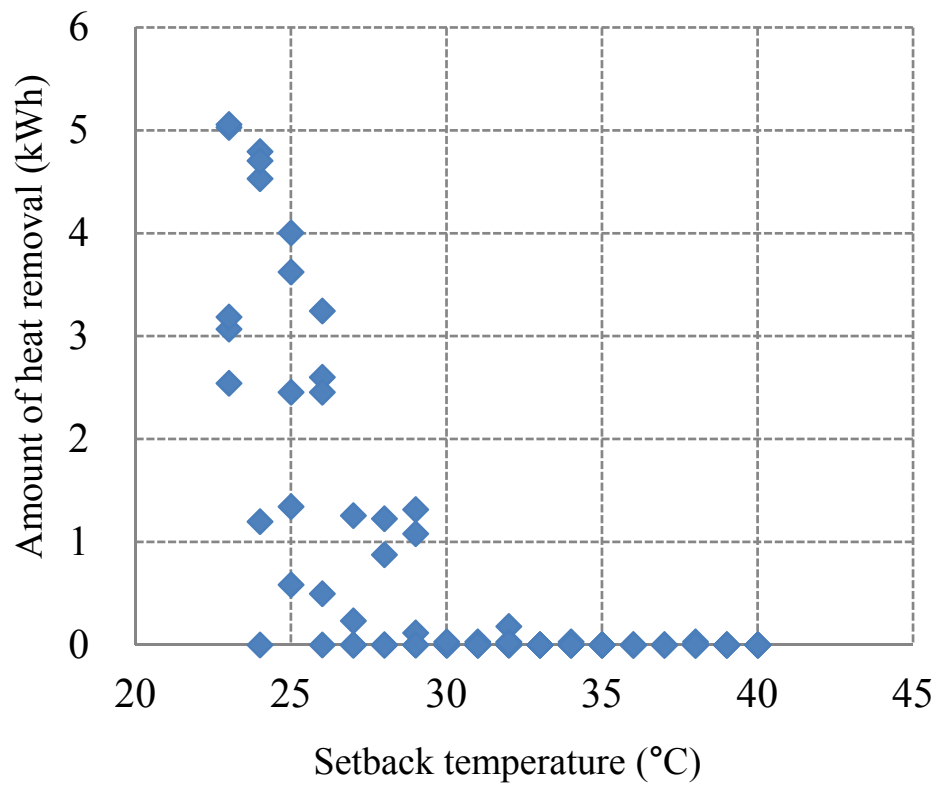

Figure 9. Relationship between the setback temperature and the amount of heat removal. 
The amount of heat removal was vastly different for the same setback temperature. For example, the amount varied from 0 to around $5 \mathrm{kWh}$ for the same $20^{\circ} \mathrm{C}$ setback temperature. This phenomenon was due to the different outdoor temperature conditions. For a day when the current and past outdoor temperatures were higher, a larger amount of heat removal was required. Thus, the outdoor temperature conditions of the current control cycle and the past cycles were used as input variables.

The simulated data $\left(\mathrm{M}_{\mathrm{i}}\right)$ were compared with the predicted data from the ANN model $\left(\mathrm{S}_{\mathrm{i}}\right)$. As shown in Figure 10, the predicted data from the ANN model (red-solid-line) had a pattern similar to that of the simulated data from the simulation model (blue-dot-line). The y-value of the chart refers to the amount of cooling energy during the setback period.

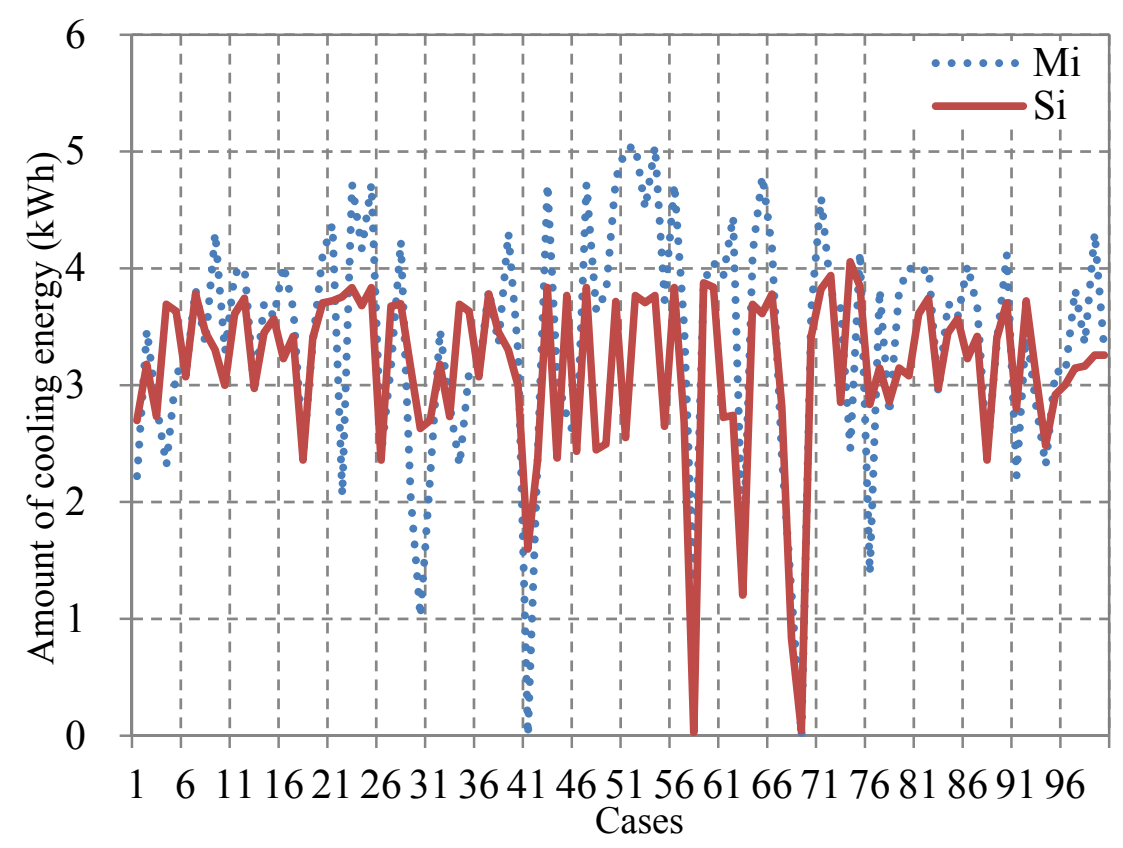

Figure 10. Comparison of the simulated results with the prediction results.

For the 100 cases, the average difference between the simulated and predicted results was $0.57 \mathrm{kWh}$, which was $17.07 \%$ of the average cooling energy of the simulation. The difference ranged from $2.47 \mathrm{kWh}$ to $0.01 \mathrm{kWh}$. The CVRMSE was $21.32 \%$ for the 100 cases. Based on the proposal in the previous study of around $25 \%$ as a statistically meaningful value for supporting the applicability of the model [44], the prediction accuracy of the ANN model in this study was validated with a $17.07 \%$ average difference and a $21.32 \%$ CVRMSE. Thus, the ANN model showed the potential for successful application to the thermal control logic for employing the most energy-efficient setback temperature.

\section{Conclusions}

This study was conducted to develop an artificial neural network (ANN)-based prediction model that can calculate the amount of cooling energy needed during the setback period of accommodation buildings. By comparing the amounts of energy needed for diverse setback temperatures, the most energy-efficient optimal setback temperature was found and could be applied in the thermal control logic. Three major processes took place for developing and optimizing the ANN model, and for testing its prediction performance, respectively. The findings are summarized as follows. 
(1) The initial ANN model for predicting the amount of cooling energy needed was developed to have nine input neurons, which were strongly related to the output neuron, 19 hidden neurons, one hidden layer, and one output neuron. In addition, a 0.6 learning rate and a moment of 0.4 were used for the learning methods;

(2) Through the optimization process using the parametrical analysis of the prediction performance of the initial ANN model, the model was modified to have three hidden layers, a 0.6 learning rate, and a moment of 0.2 , which presented the lowest CVRMSE value between the simulated results $\left(\mathrm{M}_{\mathrm{i}}\right)$ and the predicted results $\left(\mathrm{S}_{\mathrm{i}}\right)$;

(3) The performance tests of the optimized ANN model showed that it presented a lower CVRMSE value under the generally accepted levels. Thus, the prediction accuracy of the developed ANN model was proven, so when the model is applied to the thermal control logic, the most energy-efficient setback temperature is expected to be used.

From the development and evaluation process, the optimized ANN model in this study presented its prediction accuracy and potentials applicable to the control logic. A further study is required for developing the thermal control logic after applying the proposed ANN model and for testing its performance. The performance tests need to be conducted by applying the model to real buildings and to the numerical computer simulation method. Using the extensive data analysis from the real building and computer simulation, the stability of the model such as an over-fitting problem will be thoroughly investigated, and based on which, the applicability of the proposed model will be supported. In addition, the ANN model and the thermal control logic will be developed to cover the heating system. After the application of the predictive and adaptive control logics, the indoor thermal environment of accommodation buildings is expected to be conditioned more energy-efficiently.

\section{Acknowledgments}

This research was supported by the Basic Science Research Program through the National Research Foundation of Korea (NRF) funded by the Ministry of Education, Science and Technology (grant number: 2015R1A1A1A05001142) and by DMC R\&D Center at Samsung Electronics.

\section{Author Contributions}

All authors participated in preparing the research from the beginning to ends, such as establishing research design, method and analysis. All authors discussed and finalized the analysis results to prepare manuscript according to the progress of research.

\section{Conflicts of Interest}

The authors declare no conflict of interest. 


\section{Nomenclature:}

TEMPSETBACK $_{\text {SEM }}$

TEMPouT, nStep

TEMPout, AVE, nStep-60 nStep-1

TEMPout, AVE, nStep-120 nStep-61

TEMPout, AVE, nStep-180 nStep-121

TEMPout, AVE, nStep-240 nStep-181

TEMPout, AVE, nStep-300 nStep-241

TEMPout, AVE, nStep-360 nStep-301 PERIODSETBACK

\section{ENSETBACK}

$\mathrm{N}_{\mathrm{i}}$

$\mathrm{Nh}_{\mathrm{h}}$

$\mathrm{N}_{\mathrm{o}}$

VALACT

VALMIN

VALmax

$\mathrm{S}_{\mathrm{i}}$

$\mathrm{Mi}_{\mathrm{i}}$

MAVE

$\mathrm{n}$ setback temperature, ${ }^{\circ} \mathrm{C}$

outdoor air temperature in the current control cycle, ${ }^{\circ} \mathrm{C}$ average outdoor air temperature from nStep-60 to nStep- $1,{ }^{\circ} \mathrm{C}$ average outdoor air temperature from nStep-120 to nStep- $61,{ }^{\circ} \mathrm{C}$ average outdoor air temperature from nStep-180 to nStep- $121,{ }^{\circ} \mathrm{C}$ average outdoor air temperature from nStep-240 to nStep- $181,{ }^{\circ} \mathrm{C}$ average outdoor air temperature from nStep-300 to nStep-241, ${ }^{\circ} \mathrm{C}$ average outdoor air temperature from nStep-360 to nStep-301, ${ }^{\circ} \mathrm{C}$ setback period during the daytime, minutes

predicted amount of cooling energy consumption during the setback period, $\mathrm{kWh}$

number of neurons in the input layer number of neurons in the hidden layer number of neurons in the output layer actual value of each input variable minimal value of each input variable maximal value of each input variable value predicted by the ANN model numerically simulated value average of $\mathrm{M}_{\mathrm{i}}$ number of cases

\section{References}

1. Moon, J.W.; Kim, J.J. ANN-based thermal control methods for residential buildings. Build. Environ. 2010, 45, 1612-1625.

2. Moon, J.W.; Yoon, S.H.; Kim, S. Development of an artificial neural network model based thermal control logic for double skin envelopes in winter. Build. Environ. 2013, 61, 149-159.

3. Shameri, M.A.; Alghoul, M.A.; Sopian, K.; Fauzi, M.; Zain, M.; Elayeb, O. Perspectives of double skin façade systems in buildings and energy saving. Renew. Sustain. Energy Rev. 2011, 15, 1468-1475.

4. Fallahi, A.; Haghighat, F.; Elsadi, H. Energy performance assessment of double-skin façade with thermal mass. Energy Build. 2010, 4, 1499-1509.

5. Moon, J.W. ANN-Based Model-Free Thermal Controls for Residential Buildings. Ph.D. Thesis, Taubman College of Architecture and Urban Planning, University of Michigan, Ann Arbor, MI, USA, 2009.

6. McCulloch, W.; Pitts, W. A logical calculus of ideas immanent in nervous activity. Bull. Math. Biophys. 1943, 5, 115-133. 
7. Moon, J.W.; Jung, S.K.; Kim, Y.; Han, S. Comparative study of artificial intelligence-based building thermal control methods-Application of fuzzy, adaptive neuro-fuzzy inference system, and artificial neural network. Appl. Therm. Eng. 2011, 31, 2422-2429.

8. Kalogirou, S.A.; Neocleous, C.C.; Schizas, C.N. Building heating load estimation using artificial neural networks. In Proceedings of the International Conference CLIMA 2000, Brussels, Belgium, 30 August-2 September 1997; pp. 1-8.

9. Shin, K.W.; Lee, Y.S. The study on cooling load forecast of an unit building using neural networks. Int. J. Air Cond. Refrig. 2003, 11, 170-177.

10. Kim, S.H.; Kim, B.S. Building load prediction using artificial neural networks in office renovation. In Proceeding of 3rd International Symposium on Architectural Interchanges in Asia. The Architectural Institute of Korea, Cheju, Korea, 23-25 February 2000; pp. 604-612.

11. Datta, D.; Tassou, S.A.; Marriott, D. Application of neural networks for the prediction of the energy consumption in a supermarket. In Proceedings of the International Conference CLIMA 2000, Brussels, Belgium, 30 August-2 September 1997; pp. 98-107.

12. Kalogirou, S.A.; Bojic, M. Artificial neural networks for the prediction of the energy consumption of a passive solar building. Energy 2000, 25, 479-491.

13. Kreider, J.F.; Wang, X.A.; Anderson, D.; Dow, J. Expert systems, neural networks and artificial intelligence applications in commercial building HVAC operations. Autom. Constr. 1992, 1, 225-238.

14. Aydinalp, K.M.; Ugursal, V.I. Comparison of neural network, conditional demand analysis, and engineering approaches for modeling end use energy consumption in the residential sector. Appl. Energy 2008, 85, 271-296.

15. Aydinalp, M.; Ugursal, V.I.; Fung, A.S. Modeling of the space and domestic hot-water heating energy-consumption in the residential sector using neural network. Appl. Energy 2004, 79, $159-178$.

16. Platon, R.; Dehkordi, V.R.; Martel, J. Hourly prediction of a building's electricity consumption using case-based reasoning, artificial neural networks and principal component analysis. Energy Build. 2015, 92, 10-18.

17. Jovanović, R.Ž.; Sretenović, A.A.; Živković, B.D. Ensemble of various neural networks for prediction of heating energy consumption. Energy Build. 2015, 94, 189-199.

18. Yuce, B.; Li, H.; Rezgui, Y.; Petri, L.; Jayan, B.; Yang, C. Utilizing artificial neural network to predict energy consumption and thermal comfort level: An indoor swimming pool case study. Energy Build. 2014, 80, 45-56.

19. Pandey, S.; Hindoliya, D.A.; Mod, R. Artificial neural networks for predicting indoor temperature using roof passive cooling techniques in buildings in different climatic conditions, Appl. Soft Comput. 2012, 12, 1214-1226.

20. Ferreira, P.M.; Ruano, A.E.; Silva, S.; Conceição, E.Z.E. Neural networks based predictive control for thermal comfort and energy savings in public buildings. Energy Build. 2012, 55, 238-251.

21. Morel, N.; Bauer, M.; El-Khoury, M.; Krauss, J. Neurobat, a predictive and adaptive heating control system using artificial neural networks. Int. J. Sol. Energy 2001, 21, 161-201.

22. Argiriou, A.A.; Bellas-Velidis, I.; Kummert, M.; Andre, P. A neural network controller for hydronic heating systems of solar buildings. Neural Netw. 2004, 17, 424-440. 
23. Argiriou, A.A.; Bellas-Velidis, I.; Balaras, C.A. Development of a neural network heating controller for solar buildings. Neural Netw. 2000, 13, 811-820.

24. Ben Nakhi, A.E.; Mahmoud, M.A. Energy conservation in buildings through efficient A/C control using neural networks. Appl. Energy 2002, 73, 5-23.

25. Abbassi, A.; Bahar, L. Application of neural network for the modeling and control of evaporative condenser cooling load. Appl. Therm. Eng. 2005, 25, 3176-3186.

26. Chow, T.T.; Lin, Z.; Song, C.L.; Zhang, G.Q. Applying neural network and genetic algorithm in chiller system optimization. In Proceedings of the Seventh International Building Performance Simulation Association, Rio de Janeiro, Brazil, 13-15 August 2001; pp. 1059-1065.

27. Ruano, A.E.; Crispim, E.M.; Conceicao, E.Z.E.; Lucio, M.M., Jr. Prediction of building's temperature using neural networks models. Energy Build. 2006, 38, 682-694.

28. Moon, J.W.; Han, S. A comparative study between thermostat/hygrometer-based conventional and artificial neural network-based predictive/adaptive thermal controls in residential buildings. J. Asian Archit. Build. Eng. 2012, 11, 169-176.

29. Marvuglia, A.; Messineo, A.; Nicolosi, G. Coupling a neural network temperature predictor and a fuzzy logic controller to perform thermal comfort regulation in an office building. Build. Environ. 2014, 72, 287-299.

30. Huang, H.; Chen, L.; Hu, E. A neural network-based multi-zone modelling approach for predictive control system design in commercial buildings. Energy Build. 2015, 97, 86-97.

31. Li, N.; Xia, L.; Shiming, D.; Xu, X.; Chan, M. On-line adaptive control of a direct expansion air conditioning system using artificial neural network. Appl. Therm. Eng. 2013, 53, 96-107.

32. Mohanraj, M.; Jayaraj, S.; Muraleedharan, C. Applications of artificial neural networks for refrigeration, air-conditioning and heat pump systems-A review. Renew. Sustain. Energy Rev. 2012, 16, 1340-1358.

33. Yang, J.; Rivard, H.; Zmeureanu, R. Online building energy prediction using adaptive artificial neural networks. Energy Build. 2005, 37, 1250-1259.

34. Moon, J.W.; Lee, J.H.; Yoon, Y.; Kim, S. Determining optimum control of double skin envelope for indoor thermal environment based on artificial neural network. Energy Build. 2014, 69, 175-183.

35. Moon, J.W. Performance of ANN based predictive and adaptive thermal control methods for disturbances in and around residential buildings. Build. Environ. 2011, 48, 15-26.

36. Baik. Y.K.; Moon, J.W. Development and performance evaluation of optimal control logics for the two position and variableheating systems in double skin façade buildings. Int. J. Korea Inst. Ecol. Archit. Environ. 2014, 14, 71-77.

37. Moon, J.W. Development of integrated control methods for the heating device and surface openings based on the performance tests of the rule-based and artificial-neural-network-based control logics. Int. J. Korea Inst. Ecol. Archit. Environ. 2014, 14, 97-103.

38. Moon, J.W.; Han, S. Thermostat strategies impact on energy consumption in residential buildings. Energy Build. 2011, 43, 338-346.

39. MathWorks. MATLAB 14. Available online: http://www.mathworkgs.com/ (accessed on 5 February 2013).

40. University of Wisconsin. TRNSYS16.1. Available online: http://sel.me.wisc.edu/trnsys/ (accessed on 19 December 2013). 
41. Design of environmental friendly houses and guidelines for performance evaluation; Ministry of Land, Transport and Maritime Affairs of Korea: Gwachon, Korea, 2009.

42. Alpine. Sizing estimator for heating \& cooling equipment Available online: http://www.alpinehomeair.com/view.cfm?objID=4A176770-C3EB-4E97-AAED-C34B81D7AFED/ (accessed on 15 June 2014).

43. Yang, I.H.; Yeo, M.S.; Kim, K.W. Application of artificial neural network to predict the optimal start time for heating system in building. Energy Convers. Manag. 2003, 44, 2791-2809.

44. Chang, J.A. Study on the Thermal Comfort and Ventilation Performance of an Underfloor Air Supply System. Ph.D. Thesis, Taubman College of Architecture and Urban Planning, University of Michigan, Ann Arbor, MI, USA, 2007.

(C) 2015 by the authors; licensee MDPI, Basel, Switzerland. This article is an open access article distributed under the terms and conditions of the Creative Commons Attribution license (http://creativecommons.org/licenses/by/4.0/). 